\title{
CHAW NGÜNECHEN: PERSPECTIVA DE DIOS PADRE EN EL PUEBLO MAPUCHE
}

\author{
Carlos Huenupi, OFM.CAP. ${ }^{1}$
}

"Las creencias referentes al Ser Supremo y a los espíritus preocupan sobremanera al mapuche... A medda que su vida transcurre, debe mantenerse relacionado con el orden preestableccido y su dependencia se hace cada vez más consciente" 2

La vida cotidiana del mapuche está empapada de la presencia del Padre Dios. Sus expresiones de fe dan cuenta de que Chaw Ngünechen es el único sustento que gobierna la naturaleza. El mapuche que dice Chaw Ngünechen está indicando su procedencia y aceptando que es Dios quien lo ha puesto en este mundo. Por eso que la naturaleza y el mundo son sagrados para el mapuche.

\section{A. UN POCO DE HISTORIA}

Sabemos en la actualidad, que el primer gran desconcierto sufrido por los pueblos indigenas del continente durante la Conquista fue el rechazo de su pasado y de su itinerario espiritual. Primero por ignorancia, después por una deliberada y sistemática política de rechazo y demonización de toda su herencia religiosa.

En un primer momento es el mismo Colón quien escribe en su diario el día 12 de octubre de 1492 al observar a la gente que recién está conociendo: “... me parece que no tienen ninguna religión" ${ }^{3}$. Esta afirmación invita a evocar las expresiones del apóstol San Pablo cuando se dirige a los atenienses: "Ciudadanos de Atenas: veo que ustedes son personas sumamente religiosas..." (Hch 17,22). La actitud inversa de Colón respecto a la del apóstol Pablo lanzó al mundo indigena americano a una profunda conmoción y desorientación.

Más directamente en el caso mapuche tenemos al poeta y conquistador Alonso de Ercilla quien afirma que los mapuches eran "gente sin Dios ni ley"4. De hecho, los

Ponencia presentada en el V Coloquio de Teología "Dios como Padre. Perspectivas para la evangelización", organizado por el Instituto de Estudios Teológicos de la Universidad Católica de Temuco, en octubre de 1999. Indigena, Temuco, p. 19. 
misioneros hasta muy entrado el siglo XIX abrigaron la idea de que los mapuches no tenían religión propiamente tal, con la excepción de lo que se puede deducir claramente de los escritos del P. Luis de Valdivia ${ }^{5}$. Es comprensible, entonces, que se sumaran las imprecisiones de los diversos autores que buscaron hacer alguna descripción del mundo religioso mapuche.

Con estas vicisitudes históricas se ha vivido y se ha desarrollado el concepto de Dios Padre en el pueblo mapuche.

\section{B. Algunos presupuestos}

Hay otro antecedente que considero importante tener en cuenta. Se trata del modo cómo se transmite la religión mapuche de una generación a otra. En ella la tradición oral cumple un rol fundamental. La ausencia de un material escrito nos impide acceder a una reflexión sistematizada de primera fuente. Lo que tenemos son reflexiones o investigaciones sobre el tema a la luz de la cosmovisión y las prácticas religiosas mapuches. En este sentido, es muy valioso el trabajo realizado por autores mapuches.

Otro de los presupuestos importantes que debemos tener en cuenta para un acercamiento a la religión mapuche es que uno de los rasgos fundamentales de la cultura mapuche es la gran flexibilidad que existe en los conceptos que designan espacios o entidades superiores. No podemos exigir rigidez de conceptos sino más bien profundidad en la significación de los términos. La misma expresión mapu, por ejemplo, expresa una diversidad de conceptos y no simplemente "tierra"6. De todos modos, siempre que tratemos de verbalizar una experiencia tan rica y tan profunda como es la experiencia de Dios descubriremos que nuestro lenguaje es limitado.

En estas razones se explica cómo la temática del Dios Padre en la religión mapuche sea tan compleja. Aún así, intentaré algunas aproximaciones. No se trata de un análisis abstracto. La fe en Dios y las expresiones religiosas mapuches tocan una fibra fundamental de toda su cosmovisión; $y$, por lo mismo, aunque este sea un tema de orden religioso no está al margen del conflicto humano.

\section{Chaw Ngünechen, origen de todo cuanto existe}

El universo real concebido por el mapuche se enmarca en una linea vertical en cuya parte superior habita la divinidad creadora y los espiritus del bien. En la zona inferior están los espíritus del mal. La tierra pasa a ser el punto de equilibrio, es el centro de la realidad cósmica, es el escenario de las actividades del mapuche y de sus relaciones con los espíritus. Esta linea vertical cósmica que comprende estas tres zonas es el conjunto de realidades creadas por la divinidad en los orígenes. Por lo tanto, el mapuche tiene una visión cósmica de su realidad total a partir de la

5

A. NOGGLER, Cuatrocientos años de misión entre los araucanos, Padre las Casas, 1972, p. 40 s.

6

D. CATRIQUIR, Encuentro Teológico, Instituto Indigena, Temuco, 1994. 
existencia de un creador bondadoso y todopoderoso, principio y origen de todos los seres y poderes del universo y, por tanto, creador del hombre y de su entorno.

En la zona superior o wenu mapu existe un nivel superior que corresponde a la habitación del Creador y dueño del universo. Para el mapuche es el principio fundamental y preexistente, es fuente y origen de todas las cosas y lo designa, por tanto, como Elchen (Creador de la gente) o Eluuma Chaw (Padre creador) ${ }^{7}$. Es una sólida creencia del mapuche que Él creó el mundo y que todo lo bueno procede del Kallfu Wenu Chaw Ngünechen; en Él está la armonía y el equilibrio. El desequilibrio está producido por la acción de seres malignos que residen en la zona inferior o Minche Mapu. Al atribuir paternidad a Ngünechen se está reconociendo y explicando el origen de las cosas.

Ahora bien, a este único Chaw Ngünechen se le representa siempre dándosele una categoría humana con cuatro formas o expresiones diferentes. Se trata de un solo principio con distintas manifestaciones ${ }^{8}$. De aquí tenemos que el mapuche invocará a Dios diciendo:

Kallfu wenu Chaw,

Kallfu wenu Ñuke,

Kallfu wenu Wentru,

Kallfu wenu Üllcha domo.

Es decir, "Padre del azul de arriba", "Madre del azul de arriba", "Joven del azul de arriba", "Doncella del azul de arriba". Expresiones que buscan afirmar y reconocer que Ngünechen es el autor y origen de todo.

De esta concepción de Dios Padre nace toda una fuente de espiritualidad para el mapuche. En este sentido hay que destacar sobretodo su relación con la naturaleza. Reconociendo a Chaw Ngünechen como creador y dueño de todo reconoce la tierra como propiedad de Dios y, por lo tanto, un lugar sagrado y centro integrador de la vida de la comunidad. La tierra, entonces, forma parte sustancial de su experiencia religiosa. La tierra es $\tilde{N} u k e$ Mapu o Madre Tierra y, por lo tanto, nunca será objeto de explotación ni de depredación.

Desde esta óptica se fundamenta su constancia, su sentido de autoridad, su modo de relacionarse con los demás y su modo de enfrentar las dificultades ${ }^{9}$. En efecto, esa sintesis de paternidad y de trascendencia de Ngünechen da estilo y profundidad a la religiosidad mapuche y orienta sus prácticas no sólo religiosas sino cotidianas. Esta experiencia de la paternidad divina está a la base de la identidad mapuche, es decir, que la identidad del mapuche como individuo y como pueblo se juega en la aceptación u olvido de la trascendencia y paternidad de Ngünechen. Todo mapuche que se reconozca como tal, orientará su vida familiar y social, desde esa experiencia fundante.

\footnotetext{
7 S. ALCAMÁN, Op.cit., p. 9.

8 R. FOESTER, Introducción a la religiosidad mapuche, Ed. Universitaria, Santiago, 1993, p.71.

9 M. ALONQUEO, Mapuche ayer y hoy, Padre las Casas, 1985, p.40.
} 
Decir Chaw Ngünechen significa decirle peñi (hermano) o lamngen (hermana) al que está próximo. De ahí que adorar hoy a Dios como Padre significa también tener derecho a la tierra y derecho a la celebración festiva de su religión.

\section{Algunos desafíos a la Fe Cristiana}

La Iglesia, desde el Concilio Vaticano II, se ha abierto a la pluralidad de las culturas. Son innumerables y admirables todas sus reflexiones que dicen relación con el tema. El mismo papa Juan Pablo II ha tenido un encuentro cercano y paterno con diversos pueblos indígenas en nuestro continente. Gracias a este esfuerzo tenemos hoy todas las herramientas para el diálogo, el respeto y la valoración de las diversas manifestaciones religiosas que han nacido y se han desarrollado en el corazón mismo de los diversos pueblos y culturas.

En consecuencia, a los cristianos en general y a los cristianos mapuches en particular nos corresponde una tarea específica de reconocimiento, valoración y aprecio de las culturas ${ }^{10}$. No se trata simplemente de hacernos admiradores de las manifestaciones religiosas de nuestro pueblo sino de descubrir cómo Dios mismo se ha ido manifestando a quienes lo han buscado. Debemos valorar con más firmeza el evangelio de Jesucristo que nos lleva a esa experiencia maravillosa de llamar a Dios Abbá (Gál 4,6). Esta posibilidad de cercanía e intimidad con Dios que nos da Jesucristo, entrañan no sólo el hecho de vivir en esa confianza en el amor sin límites de nuestro Padre Dios, sino también de asombrarnos y de conmovernos por las diversas manifestaciones de su presencia y de su obra en la historia de los pueblos.

Al mismo tiempo, es necesario apoyar el derecho que tiene el mapuche a vivir y salvarse como mapuche. Y ya que su relación con Dios no puede separarse de su relación con la tierra, estamos llamados a sensibilizarnos por toda la problemática que hoy los mapuches enfrentan respecto al tema.

Todos podemos darnos cuenta hoy que el progreso tecnológico impide mantener la preponderancia de lo paternal en el ámbito social y familiar. La imagen de Padre está cambiando para el mapuche porque los padres de familia trabajan lejos de su hogar y se va transformando en un simple funcionario de una compleja sociedad. Debemos admitir que hay cambios pero también debemos afirmar que la figura del padre no es posible anularla. Lo que ocurre es que va asumiendo nuevos roles compatibles con un mundo en cambio. La figura del padre se seguirá grabando en el alma de los hijos como fundamento de vida y de fe. La imagen de padre otorgará siempre al pueblo mapuche una función original tanto para la fe como para la convivencia humana.

Que Dios nos ayude a todos a proclamar que no estamos viviendo en un mundo $\sin$ Padre. No somos huérfanos ni esclavos. Aquel que en diversas ocasiones y bajo diferentes formas (Heb 1,1) nos ha manifestado su paternidad nos siga conduciendo por este camino de vida y de esperanza. 